\title{
Reflexões sobre os Juramentos Utilizados nas Faculdades Médicas do Brasil
}

\author{
Reflections on the Graduation Oaths \\ Administered in Brazilian Medical Schools
}

PALAVRAS-CHAVE:

- Juramento Hipocrático;

- Ética Médica;

- Educação Médica.

KEY-WORDS:

- Hippocratic Oath;

-Ethics, Medical;

- Education, Medical.

Recebido em: 06/06/2006

Reencaminhado em: 27/11/2006

Aprovado em: 16/02/2007

\author{
Almir Galvão Vieira Bitencourt ${ }^{1}$ \\ Flávia Branco Cerqueira Serra Neves ${ }^{2}$ \\ André Yoichi Kuwano ${ }^{1}$ \\ Guilherme Soares Rebello² \\ Anna Milena Fraga ${ }^{2}$ \\ Nedy Maria Branco Cerqueira Neves ${ }^{3}$
}

\begin{abstract}
RESUMO
Objetivo: Avaliar os juramentos médicos (JM) utilizados nas faculdades de Medicina do Brasil. Métodos: Estudo descritivo, incluindo as escolas médicas brasileiras com turmas formadas até 2004. Foi enviado um questionário aos responsáveis por cada faculdade, em três diferentes tentativas de contato, por correio convencional, telefone, fax e correio eletrônico. Resultados: De um total de 96 faculdades, 48 (51,1\%) responderam ao questionário, sendo 25 destas (52,1\%) públicas. Todas as escolas utilizavam algum tipo de juramento durante o curso. Quanto ao texto utilizado: 44 faculdades (91,7\%) utilizavam o Juramento de Hipócrates (JH), trechos ou modificações deste. Trinta e oito respostas $(79,2 \%)$ continham o juramento na íntegra, que foram analisados quanto ao conteúdo. Os temas mais citados foram os princípios da beneficência e não-maleficência $(94,7 \%)$ e o segredo médico (97,4\%). Somente um juramento citava autonomia dos pacientes, e nenhum o princípio da justiça. Conclusões: A utilização de JM é amplamente difundida nas escolas médicas brasileiras, mas, ao contrário do que é visto em outros países, os textos utilizados ainda são baseados, em sua grande maioria, no JH e não abordam temas atuais importantes para a ética médica e bioética.
\end{abstract}

\begin{abstract}
Purpose: Evaluate the graduation oaths (GO) administered in Brazilian medical schools. Methods: Descriptive study covering graduations in Brazilian medical schools up to the year 2004. A questionnaire was sent to the dean of each university using three different attempts of contact: mail, fax and e-mail. Results: From a total of 96 contacted universities, 48 $(51,1 \%)$ answered to the questionnaire, 25 of which $(52,1 \%)$ public institutions. All medical schools administer some oath during the course. In relation to the text used: 44 universities (91,7\%) used the Hippocratic Oath or updated versions. Thirty eight answers to the questionnaire $(79,2 \%)$ forwarded the entire text of the oath allowing to analyze its content. The most frequently mentioned principles were beneficence, non-maleficence (94,7\%) and confidentiality (97,4\%). Only one oath expressed the principle of autonomy of the patient and none of them the principle of justice. Conclusions: The use of the GO is very common in Brazilian medical schools. However, unlike to what is observed in other countries, the greater part of texts are still based on the Hippocratic Oath and do not address current relevant ethical and bioethical principles.
\end{abstract}




\section{INTRODUÇÃO}

O mais antigo juramento médico conhecido é o tradicional Juramento de Hipócrates (JH), que é até hoje referência para a conduta médica. Criado em torno de quatro séculos antes de Cristo, o JH contém, em sua essência, os preceitos considerados fundamentais da Ética Médica, como o reconhecimento da sacralidade da vida e o respeito à dignidade humana. Baseado nesses conceitos, o juramento representa, não só para os médicos, mas principalmente para a sociedade, um fator afirmador e de compromisso com os princípios éticos vigentes ${ }^{1,2}$. Contudo, as recentes conquistas tecnológicas introduziram amplas inovações no exercício da medicina e passaram a conclamar uma revisão de seus postulados éticos. Estes elementos, juntamente com as transgressões ocorridas durante a Segunda Guerra Mundial, incentivaram o surgimento de importantes documentos que visavam resgatar os direitos humanos e a dignidade da vida, atualizando os juramentos médicos vigentes, que se mostravam omissos em relação a temas atuais de crescente importância ${ }^{3}$.

Houve um aumento do interesse no JH a partir do século 19, quando sua utilização se disseminou nas escolas médicas ocidentais ${ }^{3}$. No entanto, buscando se adequar à realidade de cada época, o JH sofreu diversas alterações ao longo dos anos, tendo algumas partes sido omitidas e outras acrescentadas ${ }^{4}$. Respeito ao paciente, compromisso em honrar a profissão e segredo médico são alguns dos ideais de Hipócrates presentes até hoje nos juramentos. Algumas partes perderam validade, como os votos de honrar seu mestre e seus filhos e provê-los financeira e intelectualmente se necessário. Temas atualmente conflitantes, como eutanásia e aborto, passaram a ser excluídos em alguns casos, enquanto outros temas não implícitos no juramento, mas que adquiriram grande importância nos dias atuais, como consentimento informado e justiça social, passaram a ser incluídos ${ }^{3-5}$. Vários autores têm discutido estas mudanças propostas no JH e, a partir daí, têm levantado questões do tipo: É necessário um juramento? Em caso positivo, deve ser um juramento de dois mil anos ou deve ser um novo? O juramento faz um médico diferente ou até melhor do que aquele que não jurou? ${ }^{6-10}$.

Apesar dessa discussão, os juramentos tem sido amplamente utilizados nas escolas médicas em todo o mundo. Cerca de $98 \%$ dos estudantes de Medicina norte-americanos (Estados Unidos e Canadá) e 50\% dos ingleses prestam algum tipo de juramento durante a graduação ${ }^{11}$. Algumas faculdades utilizam versões modernas do JH, outras utilizam a Declaração de Genebra ou ainda um juramento próprio. O processo de prestar um juramento varia: algumas escolas requerem assinatura dos estudantes, em outras o juramento é lido individualmente ou junto com os colegas de turma durante a cerimônia de formatura ${ }^{11,12}$. Vários trabalhos têm buscado estudar os juramentos utilizados atualmente em diversos países, mostrando uma importante diversidade entre os tipos de juramento empregados e seu conteúdo.

Diante desse panorama mundial e na ausência de trabalhos acerca desse tema no Brasil, torna-se necessário um estudo que avalie o perfil dos juramentos utilizados nas faculdades de Medicina de nosso país. O presente trabalho tem por objetivo avaliar a utilização de juramentos nas escolas médicas brasileiras. Além disso, visa descrever a freqüência com que as faculdades de Medicina do Brasil utilizam juramentos médicos durante a graduação, analisar em que momento do curso e de que forma os juramentos são aplicados, descrever os tipos de declarações empregadas e analisar o conteúdo dos juramentos utilizados, em comparação ao conteúdo do JH.

\section{METODOLOGIA}

Trata-se de um estudo descritivo, de corte transversal, cuja população foi composta por todas as faculdades de Medicina do Brasil com turmas formadas até 2004. A lista das faculdades foi obtida através do site da Associação Brasileira de Educação Médica (www.abem-educmed.org.br) e de lista fornecida pelo Conselho Federal de Medicina. Dados referentes às faculdades incluídas no estudo foram obtidos através dos sites: Escolas Médicas Brasileiras (www.escolasmedicas.com.br); e Associação Brasileira de Educação Médica (www.abemeducmed.org.br). As informações buscadas foram: nome da instituição, ano de fundação, estado e administração (pública ou privada).

O instrumento utilizado para a coleta foi um questionário auto-aplicável composto de cinco questões: se a faculdade utiliza algum tipo de juramento durante a graduação médica; em que momento do curso ele é aplicado; de que forma é aplicado; qual o texto utilizado (incluindo uma cópia na íntegra do juramento); se há alguma discussão com os estudantes sobre o juramento a ser prestado. Foi feita uma análise de conteúdo dos textos enviados na íntegra de acordo com temas presentes no JH e ausentes neste, mas presentes com freqüência em juramentos atuais, de acordo com estudos realizados em outros países ${ }^{13}$.

As faculdades eram incluídas no estudo se o responsável (diretor) concordasse voluntariamente em participar do mesmo, assinando o Termo de Consentimento Livre e Esclarecido, que foi enviado junto com o questionário. Ocorreram até três tentativas de contato com o responsável (diretor) por cada instituição. A primeira tentativa foi realizada por meio de correio convencional. Um segundo contato foi tentado com 
as instituições que não enviaram resposta após dois meses da primeira tentativa, através de telefone, fax e correio eletrônico. Após mais dois meses, foi realizado o terceiro e último contato por intermédio de telefone, fax e correio eletrônico. Aguardou-se mais dois meses e, na ausência de resposta, os dados da instituição foram considerados perdidos.

No processamento dos dados foi utilizado o software Statistical Packcage for Social Science (SPSS) na versão 9.0. Para caracterização, foram utilizados os parâmetros da estatística descritiva, adotando-se cálculos de freqüências simples e relativas.

\section{RESULTADOS}

Das 94 faculdades inicialmente incluídas no estudo, 50 $(53,2 \%)$ responderam ao questionário, sendo que duas $(2,1 \%)$ se recusaram a participar do estudo, restando 48 (51,1\%) escolas para análise. Não houve diferença estatisticamente significante entre as faculdades que responderam ou não em relação a região, ano de fundação ou tipo de administração. A região com maior índice de resposta foi a Sudeste $(58,0 \%)$ e a com menor índice foi a Centro-Oeste $(16,7 \%)$. Entre as escolas que participaram do estudo, 23 eram privadas $(47,9 \%)$ e 25 (52,1\%) públicas (13 federais, 8 estaduais e 4 municipais). A maioria $(60,4 \%, n=29)$ era da Região Sudeste; $20,8 \%(n=10)$ da Região Sul; $12,5 \%(n=6)$ do Nordeste; $4,2 \%(n=2)$ do Norte; e apenas $2,1 \%(n=1)$ do Centro-Oeste.

Todas as escolas utilizavam algum tipo de juramento durante a cerimônia de formatura, sendo que sete $(14,6 \%)$ também em outro momento do curso. Em 91,7\% das vezes ( $\mathrm{n}=$
44), o texto é lido em conjunto com os colegas. Apenas em duas faculdades $(4,2 \%)$ o juramento é feito no início do curso, e numa delas o juramento feito no início do curso é diferente do que é feito na colação de grau, sendo o primeiro um texto elaborado pela própria escola.

Quanto ao texto utilizado, segundo resposta fornecida no questionário, 44 faculdades $(91,7 \%)$ utilizavam o Juramento de Hipócrates, trechos ou modificações deste; duas (4,2\%) utilizavam textos próprios; e duas $(4,2 \%)$ a Declaração de Genebra. Vinte e uma faculdades (43,8\%) afirmaram haver alguma discussão do juramento utilizado com os estudantes durante a graduação. Essa discussão se dá, na maioria das vezes, em disciplinas como Ética Médica, Bioética, Medicina Legal, Antropologia Médica e História da Medicina, entre outras.

Das faculdades que responderam ao questionário, 79,2\% ( $n=38$ ) enviaram o juramento utilizado na íntegra, e neles foram analisados conteúdo e origem do texto. Desta análise, observamos que a maioria dos textos utilizados $(37,5 \%, \mathrm{n}=$ 18) consiste em uma modificação do $\mathrm{JH} ; 20,8 \%(\mathrm{n}=10)$ são fragmentos do $\mathrm{JH} ; 14,6 \%(\mathrm{n}=7)$ usam o $\mathrm{JH}$ em sua versão original; 4,2\% ( $n=2)$, a Declaração de Genebra; e 2,1\% ( $n=1)$, um texto próprio elaborado na faculdade. A análise do conteúdo desses textos revelou que os temas mais citados foram o respeito à confidencialidade dos pacientes $(97,4 \%)$ e os princípios da beneficência e não-maleficência (94,7\%). Os menos citados foram os princípios da justiça $(0,0 \%)$ e da autonomia dos pacientes $(2,6 \%)$. A Tabela 1 mostra as freqüências de todos os temas pesquisados nos textos analisados. 
TABELA 1

Análise do conteúdo dos juramentos médicos utilizados nas faculdades médicas do Brasil, com a freqüência dos temas presentes na versão original do $\mathrm{JH}$ e em outros juramentos modernos

\begin{tabular}{|c|c|}
\hline Temas & Freqüência (\%) \\
\hline Invocar uma divindade* & $26,3(\mathrm{n}=10)$ \\
\hline Compromisso com seus professores* & $31,6(n=12)$ \\
\hline Compromisso com seus discípulos* & $23,7(n=9)$ \\
\hline Princípio da beneficência* & $94,7(\mathrm{n}=36)$ \\
\hline Princípio da não-maleficência* & $94,7(\mathrm{n}=36)$ \\
\hline Proibição à eutanásia* & $18,4(\mathrm{n}=7)$ \\
\hline Proibição ao aborto* & $23,7(\mathrm{n}=9)$ \\
\hline Evitar contato sexual com pacientes* & $21,1(\mathrm{n}=8)$ \\
\hline Respeito à confidencialidade dos pacientes* & $97,4(\mathrm{n}=37)$ \\
\hline Recompensa por ser fiel ao juramento* & $94,7(\mathrm{n}=36)$ \\
\hline Punição por violar o juramento* & $94,7(\mathrm{n}=36)$ \\
\hline Compromisso com a profissão médica ${ }^{* *}$ & $7,9(n=3)$ \\
\hline Compromisso com os colegas** & $5,3(n=2)$ \\
\hline Bem-estar do paciente em primeiro lugar** & $7,9(n=3)$ \\
\hline Respeitar as leis da humanidade ${ }^{* *}$ & $7,9(n=3)$ \\
\hline Princípio da justiça ${ }^{* *}$ & - \\
\hline Respeito à autonomia do paciente ${ }^{* *}$ & $2,6(\mathrm{n}=1)$ \\
\hline Evitar discriminação de qualquer tipo** & $7,9(\mathrm{n}=3)$ \\
\hline
\end{tabular}

* Temas presentes na versão original do Juramento de Hipócrates.

** Temas ausentes na versão original do Juramento de Hipócrates, mas presentes em outros juramentos modernos.

\section{DISCUSSÃO}

Estudos realizados em diversos países apontam a utilização universal dos juramentos médicos durante o curso de graduação médica. Nos Estados Unidos e Canadá, onde esse tema foi mais bem abordado, em 1928, apenas 24\% (19 de 79) das escolas de Medicina adotavam algum tipo de juramento ${ }^{14}$. Esse número aumentou para 72\% (69 de 96) em 1958 e 90\% (115 de 128) em 197715. Em 1993, 100\% das 135 escolas médicas americanas e 80\% (12 de 15) das canadenses já faziam uso de algum tipo de juramento ${ }^{16}$. Nesses países, a utilização da versão clássica do JH é cada vez menos co- mum. Neste último estudo, Orr et al 17 . mostraram que apenas uma das faculdades ainda utilizava a versão clássica do $\mathrm{JH}$, enquanto as outras usavam principalmente modificações deste (cerca de $46 \%$ das escolas) e da Declaração de Genebra $(23 \%)^{16}$. Num estudo mais recente, feito em 141 faculdades americanas (122 alopáticas e 19 osteopáticas) em 2000, Kao e Parsi ${ }^{13}$ encontraram que metade das alopáticas (62 de 122) administravam outro juramento que não o JH ou uma modificação deste ${ }^{13}$. Trinta destas administravam um juramento escrito pelos estudantes ou pela faculdade, e 18 ofereciam mais de uma opção de juramento. 
McNeill e Dowton ${ }^{17}$, num estudo de 2002, mostraram que, das 12 escolas médicas da Austrália e Nova Zelândia, 7 utilizavam algum tipo de juramento ${ }^{17}$. Três escolas utilizavam a Declaração de Genebra ou uma modificação desta, duas usavam textos elaborados pela faculdade, baseados na Declaração de Genebra, apenas uma empregava uma modificação do JH e outra utilizava uma declaração feita por cada grupo de estudantes na época de sua formatura. Todas as sete faculdades forneciam uma versão impressa da sua declaração, e duas delas continham um espaço para os estudantes assinarem. Outro estudo, realizado na Argentina em 1997 por Rancich e Gelpi ${ }^{21}$, evidenciou que todas as dez faculdades de Medicina do país que já tinham uma turma formada usavam alguma declaração, seis delas optaram pela Declaração de Genebra, e o restante utilizava textos próprios ${ }^{18}$.

Contrariando essa tendência mundial de incentivar a utilização de textos modernos, no Brasil, a maioria absoluta dos textos empregados são fragmentos ou modificações do JH. Quando analisamos o conteúdo destes textos, percebemos ainda a ausência de princípios atualmente considerados fundamentais para a Ética Médica, como a autonomia dos pacientes e o princípio da justiça. Outros temas presentes nos juramentos modernos em outros estudos são: obstinação terapêutica, compromisso com a ciência e o ensino, cuidado da pessoa como um todo, consentimento informado e proibição à discriminação de qualquer tipo durante o exercício profissional ${ }^{16}$. Por outro lado, alguns temas oriundos do JH constituem os pilares da Ética Médica e estão presentes ainda na maioria dos textos.

Um grupo de autores buscou avaliar a presença de alguns temas em diversos juramentos médicos antigos e modernos. Pérez et $\mathrm{l}^{19}$. pesquisaram a presença do princípio da não discriminação em 50 juramentos de diferentes épocas e o encontraram em apenas 38\% deles, sendo que os juramentos modernos e contemporâneos, bem como aqueles escritos por acadêmicos expressavam mais esse compromisso ${ }^{19}$. Segundo a mesma autora, outro tema raramente presente nos juramentos é o compromisso do médico de solicitar uma remuneração justa pelo atendimento e serviços prestados na recuperação da saúde dos pacientes $^{20}$. Já Rancich et al21., analisando também juramentos antigos e modernos, destacaram a ausência do compromisso com a educação médica continuada que, segundo a autora, está intimamente relacionado à execução do princípio da beneficência, presente na maioria dos textos ${ }^{21}$. O princípio da confidencialidade, no entanto, contido no $\mathrm{JH}$, que contribui para o bemestar dos pacientes e respeita a autonomia e privacidade, encontra-se presente na maioria dos juramentos médicos de diversas épocas ${ }^{22}$ e em diversos países ${ }^{16,18}$.
No Brasil, encontramos duas faculdades de Medicina que inovaram com a criação de juramentos próprios, elaborados pelos alunos e professores de Ética Médica e Bioética dessas instituições, sendo um deles realizado no início do curso e outro no final. O primeiro, de uma escola do Nordeste, é apresentado aos estudantes antes mesmo do início do curso, numa cerimônia de recepção aos calouros e aborda temas como respeito ao paciente, responsabilidade do estudante, oposição à mercantilização da profissão e exercício ilegal da medicina. O segundo, elaborado por uma faculdade do Sul do País, surgiu a partir de questionamentos feitos pelos estudantes ao $\mathrm{JH}$, como o fato de haver compromisso com deuses do Olimpo ou a ausência de temas controversos, como aborto e eutanásia. Este juramento, utilizado desde 1999 na instituição, traz como temas principais o segredo médico, autonomia do paciente, pesquisa médica, morte e morrer, e relação médico-paciente.

Grande parte das instituições de ensino médicas norteamericanas e européias considera mais adequado para a contemporaneidade substituir o tradicional $\mathrm{JH}$ por um termo de compromissos $^{23}$. Para este grupo, parece mais sensato substituir um juramento revestido de caráter religioso por compromissos que não somente os médicos, mas toda a sociedade humana reconheça como autênticos ${ }^{24}$. Instituições representativas dos médicos na Europa e América do Norte se reuniram para lançar o Projeto de Profissionalismo Médico, que definiu como princípios fundamentais da profissão a primazia do bem-estar do paciente, sua autonomia e a justiça social. Segundo estas normas, os compromissos dos médicos são: ter competência e responsabilidade profissional; ser honesto com os pacientes e respeitar sua confidencialidade; manter uma relação médico-paciente apropriada; melhorar o acesso e a qualidade dos serviços de saúde; fazer uma distribuição justa dos recursos; incentivar o conhecimento científico; e administrar os possíveis conflitos de interesse ${ }^{24}$.

Na Holanda, por exemplo, um juramento próprio nacional foi criado por se acreditar que os juramentos existentes não mais refletiam a posição dos médicos na sociedade ${ }^{25}$. Apesar de o juramento médico não ter valor legal, ele ainda é importante por demarcar o momento em que o médico recém-formado se une aos demais profissionais e por ser um momento de reflexão acerca dos valores da profissão. Pellegrino $^{26}$ destacou algumas razões pelas quais os juramentos persistem e devem persistir, como o fato de o juramento ser uma promessa formal, empenhada por ocasião solene, na qual os diplomados médicos declaram publicamente sua dedicação aos compromissos morais da profissão, estabelecendo uma relação de confiança com o público. Além disso, um juramen- 
to também é, para esse autor, uma lembrança da continuidade de uma profissão cujas raízes estão na Antigüidade e contribui para o reconhecimento de que os médicos estarão engajados com valores que os distanciam do comércio, indústria e contratos ${ }^{26}$. Então, se, por um lado, o juramento é mantido atrelado a seu valor simbólico capaz de sustentar a medicina tradicional, como suporte para um relacionamento de confiança entre o médico e a sociedade, por outro lado, ele não mais representa para os estudantes que o proclamam um real compromisso de realização de uma prática médica ética.

Segundo Taquette et al17. 64\% dos estudantes já vivenciaram situações eticamente conflituosas durante o curso, e apenas $44 \%$ destes tiveram oportunidade ou preocupação em discutir com terceiros seu conflito, sendo que, na maioria das vezes, o debate permanece somente no espaço discente. Nesse trabalho, os temas de Ética Médica mais sugeridos para discussão pelos estudantes são relação médico-paciente, aborto, eutanásia, sigilo médico, erro médico, iatrogenias, omissão de socorro, doação de órgãos e ética e sexualidade ${ }^{27}$.

Quando questionados sobre os compromissos propostos nos juramentos atuais, os estudantes julgam como mais importantes os princípios que se referem à ética da relação médico-paciente, como o respeito pela vida humana sem qualquer tipo de preconceito. Nas últimas posições predominam princípios referentes ao compromisso com a profissão médica, as tradições e a relação com os colegas ${ }^{28,29}$. Em relação às atitudes dos estudantes e médicos frente aos juramentos médicos, Yakir e Glick ${ }^{28}$ concluíram que: a maioria dos estudantes possui uma boa perspectiva do juramento, mas acredita que ele não influencia seu comportamento profissional; a maioria dos médicos não recorda nada do que jurararm; os estudantes são favoráveis à realização do juramento durante os primeiros anos do curso; e, para que atinja seu máximo objetivo, o juramento deve ser discutido durante a formação dos estudantes 28 .

O objetivo deste trabalho foi traçar um perfil dos juramentos médicos utilizados nas faculdades brasileiras. Desta forma, para responder às perguntas formuladas na introdução sobre a necessidade de um juramento médico, tipo de juramento e sua importância na formação do profissional, seriam necessários outros tipos de estudo com objetivos e metodologias específicos. Ainda assim, pela controvérsia que o tema gera, dificilmente estas questões seriam respondidas num trabalho científico.

Na opinião dos autores do presente estudo, é, sim, necessário um juramento, um termo de compromisso que permita ao estudante ingressar no mercado de trabalho ciente da tradição e responsabilidade social de sua profissão. Para isso, no entanto, é necessário que o juramento seja um texto contextualizado com a realidade de cada época e que o estudante tenha a oportunidade de discuti-lo durante a graduação. A utilização de um juramento elaborado pelos próprios estudantes após discussão dos temas que julguem relevantes para a sua prática parece ser a melhor opção, por despertar nos estudantes a reflexão acerca dos princípios fundamentais da Ética Médica. Também não podemos responder se o médico que presta juramento terá atitudes baseadas nos preceitos éticos, mas acreditamos que aquele que tem a oportunidade de refletir sobre os ideais da profissão e escolher as premissas básicas do juramento que irá prestar fará escolhas com mais discernimento e terá um comportamento diferenciado.

O ser humano necessita de atos que marquem a passagem de uma etapa para outra (ritos de passagem). A tradição do juramento constitui a entrada formal na profissão, como um laço com a história da Medicina, e permite reconhecer a confiança da sociedade no médico. Poucas faculdades de Medicina dão oportunidade a seus alunos de refletir sobre a importância desse ato em si, sobre a evolução, formulação de princípios éticos contidos no texto do juramento que utilizam. Este tipo de reflexão pode contribuir para uma melhor formação moral dos estudantes, permitindo a resolução de questões complexas que estarão presentes no exercício profissional.

\section{CONCLUSÕES}

A pequena quantidade de publicações revela a pouca importância dada a este tema no Brasil. Desta forma, esperamos que o presente estudo, inédito em nosso meio, contribua para mudar esse cenário. A utilização de juramento médico é amplamente difundida nas escolas médicas brasileiras, mas, ao contrário de outros países, os textos utilizados ainda são baseados, em sua grande maioria, no JH e não abordam temas atuais relevantes para a Ética Médica e Bioética. Destacamos a importância de discutir os juramentos durante a graduação, proporcionando aos estudantes a oportunidade de debater os compromissos que julgam essenciais a seu exercício profissional. A partir daí, caberá a eles a escolha de fazer um juramento e que tipo de juramento vão prestar. Esta reflexão é fundamental para a identificação do formando com a sua profissão e para impedir que o juramento hipocrático se torne um juramento "hipócrita" e sem valores para o estudante.

\section{AGRADECIMENTOS}

Gostaríamos de agradecer ao Cremeb, particularmente a Sra. Julia Borges, pelo apoio logístico para a execução deste trabalho; ao Dr. Izio Kowe, por ter despertado em nós o interesse em estudar os juramentos médicos; a todas as faculdades 
que responderam e colaboraram com o nosso estudo, em especial ao Prof. Márcio Almeida, pelo interesse demonstrado e materiais enviados; e a todos os colegas, integrantes da Academética (Associação dos Acadêmicos para o Estudo da Ética Médica e Bioética), pelo incentivo e sugestões para o trabalho.

\section{REFERÊNCIAS}

1. Helidonis ES, Prokopakis EP. The contribution of Hippocratic Oath in third millennium medical practice. Am J Otolaryngol 2001;22:303-305.

2. Davey LM. The Oath of Hippocrates: An Historical Review. Neurosurgery 2001; 49:554-566.

3. Sritharan K, Russel G, Fritz Z, Wong D, Rollin M, Dunning J, et al. Medical oaths and declarations. BMJ 2001;323:1440-1441.

4. Crawshaw R, Link C. Evolution of form and circumstance in medical oaths. West J Med 1996;164:452-456.

5. Markel H. "I swear by Apolo" - by taking the Hippocratic Oath. New Engl J Med 2004;350: 2026-2029.

6. Graham D. Revisiting Hippocrates, Does an Oath Really Matter? JAMA 2000;284:2841-2843.

7. Nathanson V. Why we need a new Hippocratic Oath. Medical Education 2003;37:1123-1124.

8. Colvin BT. Why we do not need a Hippocratic Oath. Medical Education 2003;37:1125-1126.

9. Loefler I. Why the Hippocratic ideals are dead. BMJ 2002;324:1463.

10. Roddy E, Jones E. On Hippocrates. Hippocratic ideals are alive and well in 21st century. BMJ. 2002;325:496.

11. Hurwitz B, Richardson R. Swearing to care: the resurgence in medical oaths. BMJ 1997;315:1671-1674.

12. Crawshaw R. The contemporary use of Medical Oaths. J Chron Dis 1970;23:145-150.

13. Kao AC, Parsi KP. Content analyses of oaths administered at U.S. Medical Schools in 2000. Acad Med 2004;79:882-887.

14. Carey EJ. The formal use of the Hippocratic Oath for medical students at commencement exercises. Bull Assoc Am Med Coll 1928;3:159-166.

15. Friedlander WJ. Oaths given by U.S. and Canadian Medical Schools, 1977: Profession of medical values. Soc Sci \& Med 1982; 16:115-120.

16. Orr RD, Pang N, Pellegrino ED, Siegler M. Use of the Hippocratic oath: a review of twentieth century practices and a content analysis of oaths administrated in medical schools in the US and Canada in 1993. J Clin Ethics 1997;8:377-388.
17. McNeill PM, Dowton SB. Declarations made by graduating medical students in Austrália and New Zealand. MJA 2002;176:123-125.

18. Rancich AM, Gelpi RJ. Analisis de los princípios éticos em juramentos médicos utilizados em las facultades de medicina de la Argentina em relacion al hipocratico. Medicina (Buenos Aires) 1998; 58:147-152.

19. Pérez ML, Gelpi RJ, Rancich AM. Discrimination in medical assistance: An overview based on medical oaths. Rev Méd Chile 2003; 131: 799-807.

20. Pérez ML, Rancich AM, Gelpi RJ. Compromiso de Retribución Justa en los Juramentos Médicos. Rev Assoc Med Bras 2004; 50: 338-343.

21. Rancich AM, Perez ML, Morales C, Gelpi RJ. Beneficence, justice, and lifelong learning expressed in medical oaths. J Contin Educ Health Prof. 2005; 25:211-220.

22. Gelpi RJ, Pérez ML, Rancich AM, Mainetti JA. Confidencialidad en los Juramentos Médicos. Medicina (B Aires) 2000;60:506-514.

23. Siqueira JE. Juramento ou compromisso? Rev Assoc Med Bras 2002; 48: 276-276.

24. Medical Professionalism Project.Medical Professionalism in the new millennium: a physicians' charter. Medical Professionalism Project. Lancet 2002; 359:520-522.

25. Westerveld HE, Briet JW, Houwaart ES, Legemaate J, Meerman ThJAM, Breetvelt EJ, et al. Dutch medical oath. Neth J Med 2005; 63: 368-371.

26. Pellegrino ED. Medical commencement oaths: shards of a fractured myth, or seeds of hope against a dispiriting future? MJA 2002;176:199.

27. Taquette SR, Rego S, Schramm FR, Soares LL, Carvalho SV. Ethically conflicting situations experienced by medical students. Rev Assoc Med Bras 2005; 51: 23-28.

28. Yakir A, Glick SM. Medical students' attitudes to the physician's oath. Medical Education 1998; 32:133-177.

29. González A, Pérez M, Rancich AM, Etchegoyen G, Barragán H. Jerarquización de los compromisos de la declaración de Ginebra. Gac Méd Méx 2003; 139: 629-633.

\section{Conflito de Interesse}

Não Declarado.

Endereço para correspondência

Almir Galvão Vieira Bitencourt

Rua Vanderlei Pinho, 181 - apto 802 - Itaigara

41815-270 - Salvador - BA

e-mails: almirgvb@oi.com.br; almirgvb@yahoo.com.br 